\title{
Ciência da Informação e cooperação científica internacional: diálogos França-Brasil
}

A edição franco-brasileira da Revista Perspectivas em Ciência da Informação em comemoração ao ano da França no Brasil propõe um diálogo entre os dois países em torno da análise das práticas de pesquisa em Ciência da Informação, do desenvolvimento e institucionalização do campo do científico.

Esse diálogo inicia-se em 2004, com a visita da Pesquisadora Viviane Couzinet ao Brasil. Na ocasião a professora, que dirige o Laboratório LERASS na Université Paul Sabatier III- Toulouse, estabeleceu contato com diversos pesquisadores brasileiros ao conhecer programas e propostas de pesquisa através da visita a alguns cursos de Pós-Graduação em Ciência da Informação.

Posteriormente, iniciou-se, sob a coordenação da pesquisadora Regina Marteleto, uma série de atividades envolvendo pesquisadores brasileiros e franceses. Dentre as atividades desenvolvidas em colaboração estão a participação em bancas de defesa de teses e dissertações, a integração de comitês científicos do capítulo francês da ISKO nos anos de 2007 e 2009, o recebimento de doutorandos e professores para estágios de pesquisa doutorais e pós-doutorais, bem como a redação de artigos científicos em co-autoria franco-brasileira.

Os pesquisadores participantes desses eventos deram início a entendimentos que culminaram na formação da Rede MUSSI - Rede Franco-Brasileira de Pesquisadores em Mediações e Usos Sociais dos Saberes e Informações (Réseau Franco-Brésilien de Chercheurs en Médiations et Usages Sociaux des Savoirs et de I' Information).

A Rede MUSSI é uma iniciativa bilateral de estudiosos brasileiros e franceses inseridos no campo de estudos da Ciência da Informação e áreas afins, interessados em temáticas de pesquisa que associam os aspectos epistemológicos, teóricos, metodológicos e práticos da informação aos interesses e necessidades da sociedade e seus diferentes segmentos. A etapa inaugural da Rede MUSSI integrou os esforços de grupos e laboratórios de pesquisa de distintas universidades brasileiras e francesas.

A primeira atividade desenvolvida pela rede foi a realização no Rio de Janeiro do I Colóquio Mediações e Usos de Saberes e Informação: um diálogo França-Brasil, no período de 4 a 7 de novembro de 2008. O Colóquio, aberto a pesquisadores da área de Ciências da Informação e áreas correlatas, reuniu pesquisadores seniores, doutorandos e recémdoutores em torno dos seguintes objetivos: criar um espaço de encontro e de diálogo entre pesquisadores brasileiros e franceses com respeito às questões científicas e práticas que atravessam o campo temático da rede MUSSI e discutir e divulgar as pesquisas com vistas a identificar as possíveis

Perspectivas em Ciência da Informação, v.14, número especial, p.1-4, 2009 
colaborações entre grupos, instituições, pesquisadores e estudantes inseridos em laboratórios e linhas de pesquisa dos Programas de PósGraduação no Brasil e na França.

Por olhares intercruzados o evento teve como eixo principal descortinar o cenário da institucionalização, situação atual e perspectivas da formação de pós-graduação e da pesquisa em Ciências da Informação na França e no Brasil, sendo estruturado nos seguintes eixos temáticos: mediações e usos sociais dos conhecimentos e saberes - história, epistemologia, interdisciplinaridade; mediações, acesso, apropriações, usos e organização de saberes, conhecimentos, informações na cultura e sociedades contemporâneas; redes, interações, comunicações e apropriação de informações em diferentes espaços sociais; o papel dos conhecimentos, saberes e informações para o desenvolvimento científico, social e econômico.

Como desdobramento do colóquio realizado, apresenta-se nessa edição da revista Perspectivas em Ciência da Informação uma mostra de 14 artigos (cinco franceses e nove brasileiros) que relatam as pesquisas e vivências próximas às temáticas privilegiadas pela rede MUSSI, os diálogos estabelecidos na ocasião do evento e as possibilidades vislumbradas de desenvolvimento de pesquisas, em colaboração.

Os artigos deste número especial da revista Perspectivas em Ciência da Informação visitam de forma mais ou menos sistemática, a perspectiva da pesquisa em Ciências da Informação na França e no Brasil.

O trabalho de Viviane Couzinet, professora da Universidade Paul Sabatier III, de Toulouse e diretora do Laboratoire d'études et de recherches appliquées en sciences sociales (LERASS), e também coordenadora da linha de pesquisa Médiations en information et communication spécialisées (MICS) trouxe-nos, sob o tema "Transmitir, difundir: formas de institucionalização de uma disciplina", uma bela reflexão sobre as possíveis formas de institucionalização da disciplina sciences de l'information et de la communication (SIC) a partir do aproveitamento de competências adquiridas na produção de instrumentos documentais para traçar os contornos de um campo científico. A proposta se traduz por compreender como as linguagens documentais utilizadas nas bibliotecas e na imprensa, contribuiram para divulgar a disciplina a um público mais amplo do que o das universidades onde ela esta institucionalmente já inserida.

No artigo "Ciência da Informação como área do conhecimento: abordagem no contexto da pesquisa e da pós-graduação no Brasil" Rosali Fernandez de Souza e Ida Regina Chitto Stumpf destacam o contexto institucional da pesquisa em Ciência da informação, através de um panorama dos onze programas de pós-graduação existentes atualmente no cenário nacional.

No mesmo contexto de análise o artigo "A pesquisa em Ciência da informação no Brasil: marcos institucionais, cenários e perspectivas" de Regina Maria Marteleto, enfatiza a identidade do campo em relação às Ciências Sociais do ponto de vista histórico e epistemológico e situa o papel da ANCIB e dos grupos de trabalho a ela vinculados. A autora 
assinala ainda a mudança no regime de informação no qual as organizações empresariais ganharam proeminência, cenário antes orientado pelo Estado na figura das instituições governamentais, e dos centros de formação e pesquisa públicos.

A influência da documentação francesa na consolidação dos programas de formação e no imaginário da organização da informação no Brasil, notadamente as contribuições de Paul Otlet e Jean-Claude Gardin, se apresenta nos textos "Surgimento e consolidação da Documentação: subsídios para compreensão da história da Ciência da Informação no Brasil" de Cristina Ortega e "A influência da Jean-Claude Gardin e a linha francesa na evolução do conceito de Linguagem Documentária" de Michely Jabala Mamede Vogel.

Patrick Fraysse, Sabine Roux e Caroline Courbière convidam-nos a uma viagem no contexto do patrimônio do ponto de vista comunicacional. Através do texto "A rota como memória" o processo de comunicação, enquanto rota, é portador de informação a ser decifrada e interpretada, ou seja, a ser materializada como documento, depositário da memória coletiva. Do caminhar errante, a rota enquanto documentarização mediadora de uma memória institucionalizada ou em vias de institucionalização, representa aqui produção documental de patrimonialização de um saber.

Nos artigos "Dimensões do acesso aos arquivos do Departamento de Ordem Política e Social do Estado de Minas Gerais" de Shirlene Linny da Silva e Maria Guiomar da Cunha Frota e "Construindo conhecimentos através do espaço sindical francês: um olhar sobre a informação e o papel do arquivo junto a uma política de memória militante" de Ricardo Medeiros Pimenta identificam-se as marcas do diálogo entre a França e o Brasil em torno do papel fundamental das instituições arquivísticas como vetores da memória coletiva.

Josiane Senié Demeurisse, Isabelle Fabre, Cécile Gardiès, pesquisadoras integrantes do laboratório LERASS, tratam da organização documental de periódicos de história, na sua forma em papel tanto como na sua forma digital, através do artigo « Organização do saber e mediação documental: do tratamento de periódicos de história a sua utilização em bibliotecas universitárias na França". Abordando a introdução, online, de recursos eletrônicos nas instituições e suas bibliotecas, demonstram como esses recursos alteram as práticas profissionais de tratamento da informação assim como o uso dos suportes informacionais.

O Professor e pesquisador Vicent Liquete, da Université de Bordeaux traçou-nos um panorama bastante enriquecedor sobre a formação dos professores-documentalistas do sistema educacional francês, em sua profissionalização. No artigo "Construção da prática profissional e das mediações documentais do professor documentalista francês", relata, nos últimos vinte anos, como se constrói progressivamente esta cultura profissional e científica da informação, observando as formas de mediação desenvolvidas no contexto desses atores.

Em "Mediação informacional no contexto universidade-sociedadeinovação: potencialidades, contradições e desafios" os autores Anderson 
Fabian Ferreira Higino, Alcenir Soares dos Reis, Lígia Maria Moreira Dumont e Maria Antonieta Pereira destacam a relação entre a Universidade e a inovação tomando como foco sua responsabilidade social vista a partir da centralidade das concepções de ecologia dos saberes, teorias de rede e pensamento complexo, educação, cultura, leitura e cidadania.

No artigo "Informação, tecnologia e mediações culturais" de Marcos Antônio de Almeida destaca-se a informação cultural presente na Internet bem como o lugar da tecnologia da informação e comunicação nos processos de produção, circulação e recepção dos bens simbólicos. 0 autor assinala ainda o papel da crítica no contexto da ampliação da oferta dos produtos e da presença mais efetiva dos sujeitos na difusão e organização da informação cultural.

Michèle Caria e Silvia Sigales Ruiz em seu artigo "Comunicação científica intercultural: Olhares cruzados sobre os processos psicológicos e comunicacionais", apresentam um estudo qualitativo que se inscreve nos domínios da Psicologia e das Ciências da Informação e da Comunicação. $O$ artigo é resultado de pesquisa realizada com alunos mexicanos doutorandos bolsistas e revela os processos psicológicos e comunicacionais vivenciados por esses pesquisadores fora de seus países de origem.

No artigo "Novos enfoques no campo da Ciência da informação: uma discussão sobre a aplicabilidade do conceito de regime de informação em arranjos produtivos locais" Adriane Maria Arantes de Carvalho discute a aplicabilidade dos regimes de informação e seus elementos constituintes (atores envolvidos, políticas específicas, mecanismos e instrumentos formais de sustentação das práticas interorganizacionais de disseminação e compartilhamento de conhecimento, vocabulário comum, e metas compartilhadas e transparência no ambiente legal e regulatório) em arranjos produtivos locais e suas contribuições às práticas e ações informacionais.

Acredita-se que a ampliação do diálogo internacional com a França venha contribuir para a ampliação das fronteiras epistemológicas do campo e suscitar uma produção científica em colaboração com possibilidades de redução da fratura estrutural fundamentada na divisão planetária entre norte e sul, com enormes prejuízos para a Ciência.

Nesse sentido, verifica-se que a pesquisa desenvolvida no campo da Ciência da Informação Brasileira dialoga de forma equilibrada com os demais parceiros internacionais o que amplia e permite, pela via da informação em redes de cooperação acadêmicas, uma presença mais efetiva das questões informacionais e de institucionalização da disciplina no cenário mundial.

Maria Aparecida Moura e Marta M. Kerr Pinheiro 